\title{
Modeling Small-Scale Dairy Farms in Central Mexico Using Multi-Criteria Programming
}

\author{
D. Val-Arreola, ${ }^{*} E$. Kebreab, $\dagger^{1}$ and J. France $\dagger$ \\ *School of Agriculture, Policy and Development, The University of Reading, Earley Gate, Reading, RG6 6AR, UK \\ †Centre for Nutrition Modelling, Department of Animal and Poultry Science, University of Guelph, Guelph, Ontario, N1G 2W1, Canada
}

\begin{abstract}
Milk supply from Mexican dairy farms does not meet demand and small-scale farms can contribute toward closing the gap. Two multi-criteria programming techniques, goal programming and compromise programming, were used in a study of small-scale dairy farms in central Mexico. To build the goal and compromise programming models, 4 ordinary linear programming models were also developed, which had objective functions to maximize metabolizable energy for milk production, to maximize margin of income over feed costs, to maximize metabolizable protein for milk production, and to minimize purchased feedstuffs. Neither multicriteria approach was significantly better than the other; however, by applying both models it was possible to perform a more comprehensive analysis of these small-scale dairy systems. The multi-criteria programming models affirm findings from previous work and suggest that a forage strategy based on alfalfa, ryegrass, and corn silage would meet nutrient requirements of the herd. Both models suggested that there is an economic advantage in rescheduling the calving season to the second and third calendar quarters to better synchronize higher demand for nutrients with the period of high forage availability.
\end{abstract}

Key words: small-scale dairy farm, multi-criteria programming, Mexico

\section{INTRODUCTION}

In Mexico, national milk production has increased in the last 5 yr but demand has increased at a higher rate, resulting in about $35 \%$ of milk consumed being imported (Gallardo-Nieto et al., 2004). Such a situation within the North America Free Trade Agreement is causing the Mexican dairy sector to face major challenges to stay competitive. Small-scale dairy enterprises contribute between 35 and $40 \%$ of the national

Received June 29, 2005.

Accepted November 14, 2005.

${ }^{1}$ Corresponding author: ekebreab@uoguelph.ca milk production. They represent an important source of employment and are enhancers of Mexican rural families' livelihoods. They have several advantages that contrast with intensive systems: i) small-scale dairy enterprises have relatively low production costs; ii) they are highly integrated with crop production systems; and iii) they absorb most of the family labor and require a low investment in facilities (Arriaga-Jordan and Pearson, 2002; Wiggins, 2002). Several studies have pointed to small-scale dairy systems as an important means of increasing national milk production and at the same time being competitive with international standards (e.g., Espinoza-Ortega et al., 1997; Wiggins, 2002). New approaches are required to provide insights into improving the efficiency of this type of system. Previous work has suggested considering changes related to: i) selecting the most appropriate feeding strategy according to resource availability and herd needs (ValArreola et al., 2005); ii) deciding the number of cows calving in each period of the year (Val-Arreola et al., 2004a); and iii) selecting the best forage production strategy (Val-Arreola et al., 2004b). The previous work, however, considered different aspects of the system in isolation, unlike the current study, which considers the system holistically, leading to more specific recommendations.

Few studies related to modeling agricultural systems have been carried out in Mexico, particularly concerning dairy farms. Candler (1983) attempted to optimize a whole intensive dairy farm in northern Mexico using a linear programming (LP) model designed over a 12mo horizon. The model was aimed at providing insights for government policy makers, but the detailed information required limited its applicability. Castelán-Ortega et al. (2003a) developed a simulation model to support the decision processes of small-scale dairy producers in central Mexico. However, the complexity of the model (3 submodels) and its size (more than 15,000 variables and 600 restrictions) makes the model matrix, besides being difficult to use and maintain, highly demanding of detailed information. Such information is difficult to obtain or is simply unavailable for this type of enterprise. 
Ordinary LP has been used extensively for farm planning, but it is limited to dealing with a single objective (Piech and Rehman, 1993). Therefore, a multiple criteria decision-making (MCDM) framework should be more appropriate in dealing with the multidimensional nature of agricultural systems. Although application of such techniques is not common in agriculture, the techniques do allow more realistic models than ordinary LP (Rehman and Romero, 1993).

The primary aim of this study was to use the MCDM approach (considering objectives: maximize $\mathrm{ME}$ for milk production, maximize margin of income over feed costs, maximize MP for milk production, and minimize purchased feedstuffs) to assist the decision process in small-scale dairy farms in central Mexico. The decisions considered related to selecting the best forage production strategy capable of providing most of the nutrients required by the herd and determining the number of cows calving in each period of the year to match their requirements with nutrient availability through the most appropriate feeding strategy.

\section{MATERIALS AND METHODS}

Two MCDM techniques were used, goal programming (GP) and compromise programming (CoP), to examine whether a single optimal solution or a set of nearly optimal solutions could better achieve the objectives proposed. Goal programming deals with different goals that are included in the GP model as approximate equalities; $\mathrm{CoP}$ seeks to determine a good compromise between different objectives rather than optimizing one of them.

\section{Technical Coefficients}

Technical coefficients correspond to a typical smallscale dairy farm located in Michoacan State, central Mexico. These enterprises comprise two basic components, one livestock production and the other crop production, with both being strongly interrelated (Val-Arreola et al., 2004a). Regarding the livestock component, herd size averaged 13 mature cows with a live weight of $550 \mathrm{~kg}$ and a milk yield of $14 \mathrm{~L} / \mathrm{d}$ over a lactation period of 305 d (Méndez-y-Cazarín et al., 2000). Using this basic information, DM intake, ME, and MP requirements were calculated according to AFRC (1993). Requirements were calculated to meet maintenance, milk production, weight change, and pregnancy needs in each month of pregnancy and lactation. Val-Arreola et al. (2004c) reported that the lactation equation of Dijkstra et al. (1997) was the most appropriate for small-scale farms in Mexico and was adopted to determine milk production requirements. Maintenance re- quirements were calculated using live weight changes. Regarding the crop component, average land surface was assumed to be 5.9 ha, and crops were grown in 2 cropping cycles, spring-summer and autumn-winter. Table 1 shows the cultivated crops and their technical coefficients considered in this study, which were taken from Val-Arreola et al. (2004b).

\section{Constraints}

The process of constructing the MCDM models began by defining a set of constraints using a standard LP model framework. The year was divided into 4 periods or quarters, each 91 d. Each cropping cycle covered 2 quarters.

Nutrient requirements were established for the cow in each quarter by summing monthly values. Stage of lactation was established by considering 4 periods: calved plus dry-off (comprising a dry-off period of $59 \mathrm{~d}$ plus the first $32 \mathrm{~d}$ of lactation), first one-third, second one-third, and last one-third (each one of $91 \mathrm{~d}$ ).

Constraints are shown in Appendix 1. Both inequalities (1) and (2) are similar in that the diet must cover maintenance, pregnancy, lactation, and weight change requirements for ME and MP. The DM intake constraint (3) ensures that DM intake requirement is met by the feeds selected by the model.

Results of studies carried out on farm have shown that $\mathrm{N}$ excreted by these small-scale systems is more than 3 times the Mexican standard due to confined space for housing cows and deficiencies in manure management (Méndez-y-Cazarín et al., 2000). To incorporate this element into the model, the equation suggested by Kebreab et al. (2001) was used to estimate N excretion from $\mathrm{N}$ intake. Appendix 1 shows the constraint formulated for $\mathrm{N}$ excretion. The left hand side of the inequality (4) was taken from Kebreab et al. (2001) and the constraint based on Méndez-y-Cazarín et al. (2000), who calculated that a typical small-scale dairy herd with cows averaging $585 \mathrm{~kg}$ in liveweight produces about $428 \mathrm{~kg}$ of $\mathrm{N}$ per quarter. Constraint (5) ensures that the amount of homegrown feed required does not exceed the capacity of crops grown on the land available.

Constraints related to crop production were formulated to ensure coherent land distribution from the solution provided by the model; that is, to avoid conflicts between different cropping areas suggested by the solution. Therefore, restrictions represented by equations (6) and (7) have the purpose of allocating the same land surface to a given crop in both quarters of the cropping cycle. Constraint (8) was formulated to distribute the area for perennial and annual crops realistically. If the solution selects alfalfa (hay or fresh cut), the area used for this crop need to be the same in all quarters, which 
Table 1. Technical coefficients for crops grown on small-scale dairy enterprises in central Mexico

\begin{tabular}{|c|c|c|c|c|c|c|c|c|}
\hline & \multicolumn{2}{|c|}{ Fresh alfalfa } & \multicolumn{2}{|c|}{ Alfalfa hay } & \multicolumn{2}{|c|}{ Fresh ryegrass } & \multicolumn{2}{|c|}{ Oat hay } \\
\hline \multicolumn{9}{|l|}{ Spring-summer } \\
\hline DM (kg) & 9,280 & 4,640 & 10,000 & 5,000 & 13,000 & 6,500 & 6,300 & 6,300 \\
\hline $\mathrm{ME}(\mathrm{MJ})$ & 77,655 & 38,828 & 77,655 & 38,828 & 130,541 & 65,271 & 50,346 & 50,346 \\
\hline $\mathrm{CP}(\mathrm{kg})$ & 1,390 & 695 & 1,500 & 750 & 1,950 & 975 & 430 & 430 \\
\hline Cost per ha $(\mathrm{M} \$)$ & 2,372 & 1,186 & 3,966 & 1,983 & 2,118 & 1,059 & 4,273 & 4,273 \\
\hline & \multicolumn{2}{|c|}{ Fresh alfalfa } & \multicolumn{2}{|c|}{ Alfalfa hay } & \multicolumn{2}{|c|}{ Corn grain/straw } & \multicolumn{2}{|c|}{ Corn silage } \\
\hline & per ha & per $q r^{1}$ & per ha & per $q r$ & per ha & per qr & per ha & per qr \\
\hline \multicolumn{9}{|l|}{ Fall-winter } \\
\hline Fresh matter (kg) & 21,200 & 10,600 & 8,880 & 4,440 & 8,380 & 8,380 & 37,400 & 37,400 \\
\hline $\mathrm{DM}(\mathrm{kg})$ & 7,420 & 3,710 & 8,000 & 4,000 & 7,290 & 7,290 & 10,850 & 10,850 \\
\hline
\end{tabular}

${ }^{1} \mathrm{qr}=$ Calendar quarter.

is the purpose of constraint (9). The crop cost component in the model is regulated by (10).

Constraint (11) ensures the number of cows calving in each quarter does not exceed the herd size. Restriction (12) and (13) were formulated to ensure the number of cows at a given lactation stage in a given calendar quarter was not greater than in the previous stage in the previous quarter. Constraint (14) aims to maintain at least a minimum production of milk in each quarter.

\section{Pay-Off Matrix and Initial Solutions}

Definition of the pay-off matrix (Table 2) commenced by selecting 4 objectives to be optimized: i) maximization of ME for milk production, ii) maximization of margin of income over feed costs, iii) maximization of MP for milk production, and iv) minimization of the purchase of feedstuffs. These objectives were considered the most appropriate for modeling a representative small-scale dairy farm. Use of GP and $\mathrm{CoP}$ involves definition of targets and ideal points, respectively. The approach of Piech and Rehman (1993) was adopted, in which such values were obtained by solving conventional LP problems for each objective.

Appendix 2 shows the functions formulated for each of the objectives mentioned above. Objectives (1) and (2) were formulated assuming a sufficiency of nutrients provided by the crops to cover ME and MP requirements for maintenance, pregnancy, and weight change. The remaining ME will be utilized for milk production. Although all the objective functions are shown in Appendix 2 , only one objective was optimized at a time when the single LP models were used to create the pay-off matrix and determine the best value achieved for each objective.

\section{Goal Programming}

Goal programming is one of the most widely used MCDM techniques. Its main characteristic is its capacity to deal with different goals, which are included in the model as approximate equalities. The right hand side values are the targets that may or may not be satisfied. Thus, the purpose of GP is to minimize the

Table 2. Pay-off matrix for the 4 objective functions optimized ${ }^{1}$

\begin{tabular}{|c|c|c|c|c|}
\hline & $\begin{array}{l}\text { Maximize } \\
\text { ME }\end{array}$ & $\begin{array}{l}\text { Maximize } \\
\text { margin }\end{array}$ & $\begin{array}{l}\text { Maximize } \\
\text { MP }\end{array}$ & $\begin{array}{l}\text { Minimize } \\
\text { purchased } \\
\text { feeds }\end{array}$ \\
\hline Maximize ME for milk production (MJ) & $\underline{1,628,637}$ & 81,553 & 12,809 & 39,127 \\
\hline Maximize margin of income over feed cost $(\mathrm{M} \$)$ & 377,581 & $\underline{169,285}$ & 4,393 & 0 \\
\hline Maximize MP for milk production (kg) & $1,200,343$ & 81,553 & $\underline{14,178}$ & 53,795 \\
\hline Minimize purchased feeds ( $\mathrm{M} \$$ ) & 577,180 & 155,247 & 5,147 & 0 \\
\hline
\end{tabular}

\footnotetext{
${ }^{1}$ Optimal solutions for each objective function are underlined.
} 
deviations between achievement of the goals and their targets. Therefore, GP includes positive $\left(p_{j}\right)$ and negative $\left(n_{j}\right)$ deviation variables that indicate over-achievement or under-achievement accordingly (Romero and Rehman, 1989). Goal programming generally involves a composite objective function, in which goal satisfaction may be traded-off using relative weights on deviations from the targets. Mathematically, the GP problem can be expressed as follows:

$$
\begin{aligned}
\text { minimize } & \sum_{j=1}^{n} w_{j}\left(\frac{n_{j}+p_{j}}{g_{j}} 100\right), \\
\text { subject to } & Z_{j}(\boldsymbol{x})+n_{j}-p_{j}=g_{j} \quad \text { for all } j, \\
& \boldsymbol{x} \in \boldsymbol{F} \text { (technical constraints } \\
& \text { from Appendix 1), } \\
& \boldsymbol{x}, n_{j}, p_{j} \geq 0
\end{aligned}
$$

where $w_{j}$ is the weight of goal $j, n_{j}$ is the negative deviation variable, $p_{j}$ is the positive deviation variable, $\boldsymbol{F}$ is the feasible set, $\boldsymbol{x}$ is the vector of decision variables, $g_{j}$ is the objective target for the goal $j$, and $Z_{j}(\boldsymbol{x})$ is the objective function for the goal $j$ as defined in Appendix 2 . If all the goals have the same importance, then all the weights are the same; that is, $w_{1}=w_{2}=\ldots=w_{n}=$ 1. The general aim in GP is to minimize the deviations between achievement of the goals and their targets; thus, variable $n_{j}$ is included in the optimal basis if the $g_{j}$ target is underachieved and variable $p_{j}$ if the $g_{j}$ target is overachieved. Thus, the objective function in the model minimizes the sum of appropriate deviation variables for each goal.

\section{Compromise Programming}

Because it is most unlikely that all the objectives can be optimized simultaneously, an alternative is to seek a good compromise amongst the different objectives rather than optimizing only one of them. Compromise programming seeks to satisfy simultaneously a number of objectives subject to a given set of constraints. The objective is to find a subset of efficient solutions known as pareto-optimal or nondominated solutions from a set of feasible solutions (Romero and Rehman, 1989).

First, ideal points need to be defined using the optimal values underlined in the pay-off matrix (Table 2), to which the solution obtained by the CoP model must be as close as possible. To measure closeness, a distance function is introduced into the analysis, which minimizes the distance between the solution and the ideal points. Depending on the measure of distance used, a set of compromise solutions can be obtained (Romero et al., 1987). Two metrics were considered: $L_{1}(\geq 0)$ repre- senting the longest distance geometrically, which was minimized by solving the following LP problem (Cohon, 1978):

$$
\begin{aligned}
\operatorname{minimize} & L_{1}=\sum_{j=1}^{n} w_{j}\left(\frac{z_{j}^{*}-z_{j}(\boldsymbol{x})}{z_{j}^{*}-z_{* j}}\right) \\
\text { subject to } & \boldsymbol{x} \in \boldsymbol{F} \quad(\text { technical constraints } \\
& \text { from Appendix 1), } \\
& \boldsymbol{x} \geq 0
\end{aligned}
$$

where $\boldsymbol{F}$ is the feasible set and $\boldsymbol{x}$ is the vector of decision variables, $z_{j}^{*}$ and $z_{* j}$ are the ideal and antiideal values for objective $j$ (the ideal value was assumed to be the best value from the pay-off matrix and the antiideal the worst), $z_{j}(\boldsymbol{x})$ is the $j$ th objective function and $w_{j}(>0)$ is the weight attached to objective $j$.

The second metric used to obtain a compromise solution is $L_{\infty}$, the largest deviation from among the individual deviations. This is minimized, and the LP problem to be solved is the following (Cohon, 1978):

$$
\begin{aligned}
\text { minimize } & L_{\infty}=d_{\infty}, \\
\text { subject to } & w_{J} \frac{z_{j}^{*}-z_{j}(\boldsymbol{x})}{z_{j}^{*}-z_{* j}} \leq d_{\infty} \quad \text { for all } j \\
& \boldsymbol{x} \in \boldsymbol{F} \quad(\text { technical constraints } \\
& \text { from Appendix 1) } \\
& \boldsymbol{x}, d_{\infty} \geq 0
\end{aligned}
$$

where $d_{\infty}$ is the largest deviation. It was assumed in this study that $w_{1}=w_{2}=\ldots=w_{n}=1$ for both metrics.

\section{RESULTS}

\section{Ordinary Linear Programming}

Table 2 shows the pay-off matrix in which the optimal solutions for each objective function specified in the LP model are underlined, together with the corresponding values of the other objectives for each optimal. For example, the elements of the first row of Table 2 show that the maximum ME available for milk production is $1,628,637 \mathrm{MJ}$, which corresponds to a margin of $\mathrm{M} \$ 81,553$, MP for milk production of $12,809 \mathrm{~kg}$, and a cost of purchased feedstuffs of $\mathrm{M} \$ 39,127$. Table 2 illustrates the conflict between maximizing ME and MP and maximizing margin. Also, there is conflict between maximizing $\mathrm{ME}$ and $\mathrm{MP}$ and minimizing the cost of purchased feeds.

Table 3 shows feed cost, milk yield, feed cost per liter of milk, DM supply, and DM required when each 
Table 3. Feed cost, milk yield, DM supply, and DM required for each single objective linear programming model

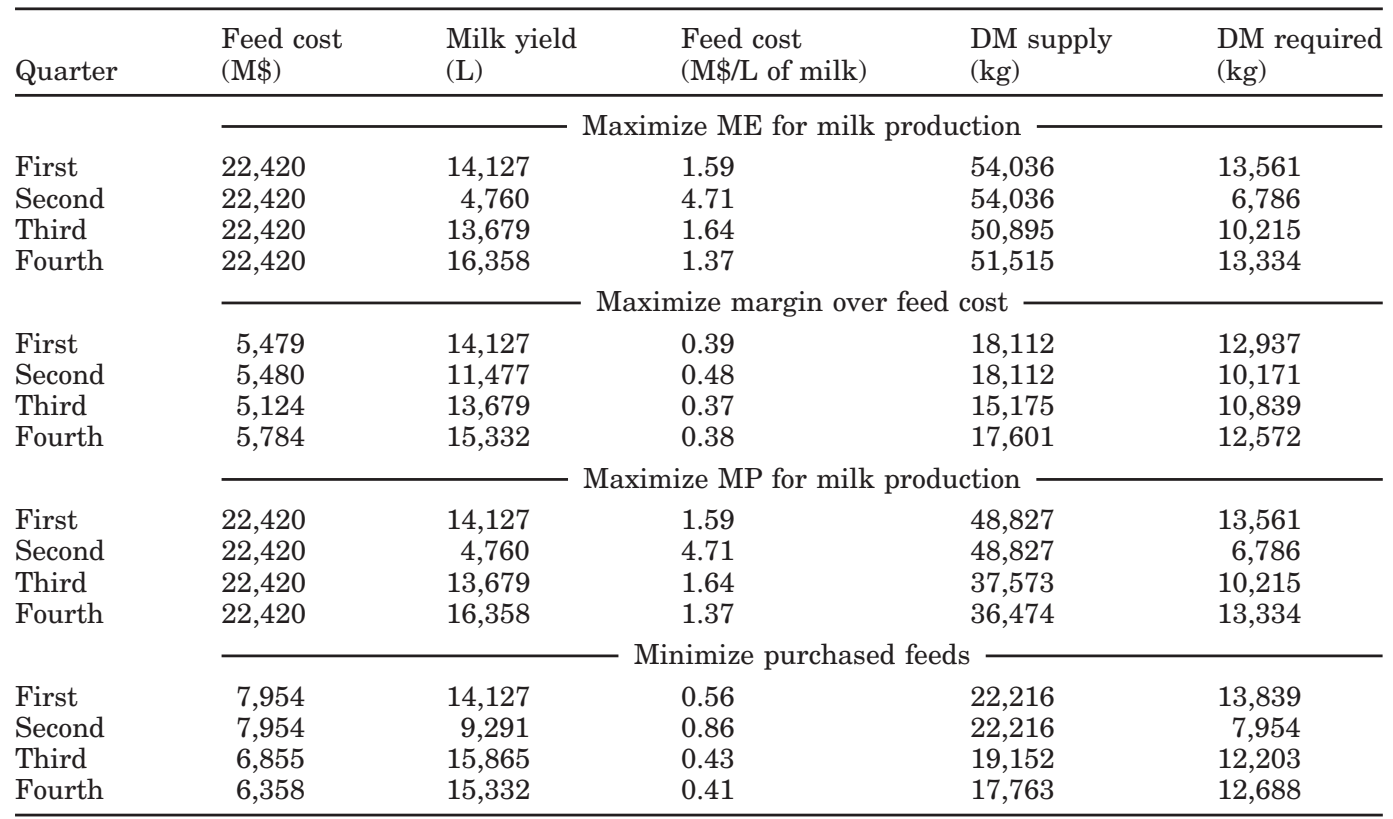

objective is optimized individually. The lowest costs were obtained by maximizing margin over feed costs and minimizing purchase of external feeds, and the most expensive ration was obtained when $\mathrm{ME}$ and $\mathrm{MP}$ were maximized. In all LP models, the most expensive quarter was the second. The models that gave a much higher DM supply than DM required by the herd were those that maximized ME and MP. The table shows the conflict between maximizing nutrient production and maximizing farm profitability.

Optimum land distribution for each objective and forage production strategies suggested by the models are shown in Figure 1. In the case of the model that maximizes $\mathrm{ME}$, the 3 crops alfalfa hay, fresh ryegrass, and corn silage were chosen. With the model that maximizes margin, the same crops were selected but less land was allocated. In the case of maximized MP, only fresh alfalfa was selected, and similarly, only one crop was selected when minimum purchased feeds was the objective. The models that maximized ME and MP provided a higher DM supply because they allocated a higher proportion of land to crops than the other 2 models. However, all the models indicate that it is possible to maintain current milk production utilizing only forage in the ration.

\section{Goal Programming}

Table 4 shows the deviational values of each goal specified in the GP model. The overachievement values obtained were margin over feed costs and cost of pur- chased feeds. The overachievement of purchased feed cost was less desired. However, overachievement of margin over feed cost represents $52 \%$ more than the desired goal. Considering the deviational values, the GP model showed a better performance than the single objective LP models. In terms of land distribution (Table 5), the GP model selects the crops fresh alfalfa, fresh ryegrass, and corn silage, like the LP model that maximizes ME for milk production but with fresh alfalfa replacing alfalfa hay (Figure 1). Obviously, this solution supplied higher quantities of DM and therefore higher quantities of ME, MP, and milk (Table 5). Excess of available DM may, in theory, be sold or offers the possibility of increasing the herd size of these farms.

Herd composition and milk production suggested by the GP model are shown in Table 6. The lowest milk production level was achieved during the second quarter and the largest in the fourth quarter. In comparing herd structure with milk yield in each quarter, it can be seen that the lowest milk production level was when most of the cows were in the calved or dry-off stage. To match forage availability with ME needs by manipulating the herd structure, the GP model suggests most of the cows should calve in the second and third calendar quarters.

\section{Compromise Programming}

Compromise solutions obtained from the $\mathrm{CoP}$ model are shown in Table 7 . Using the $L_{1}$ and $L_{\infty}$ metrics, nearest values to the ideal point for each of the objec- 

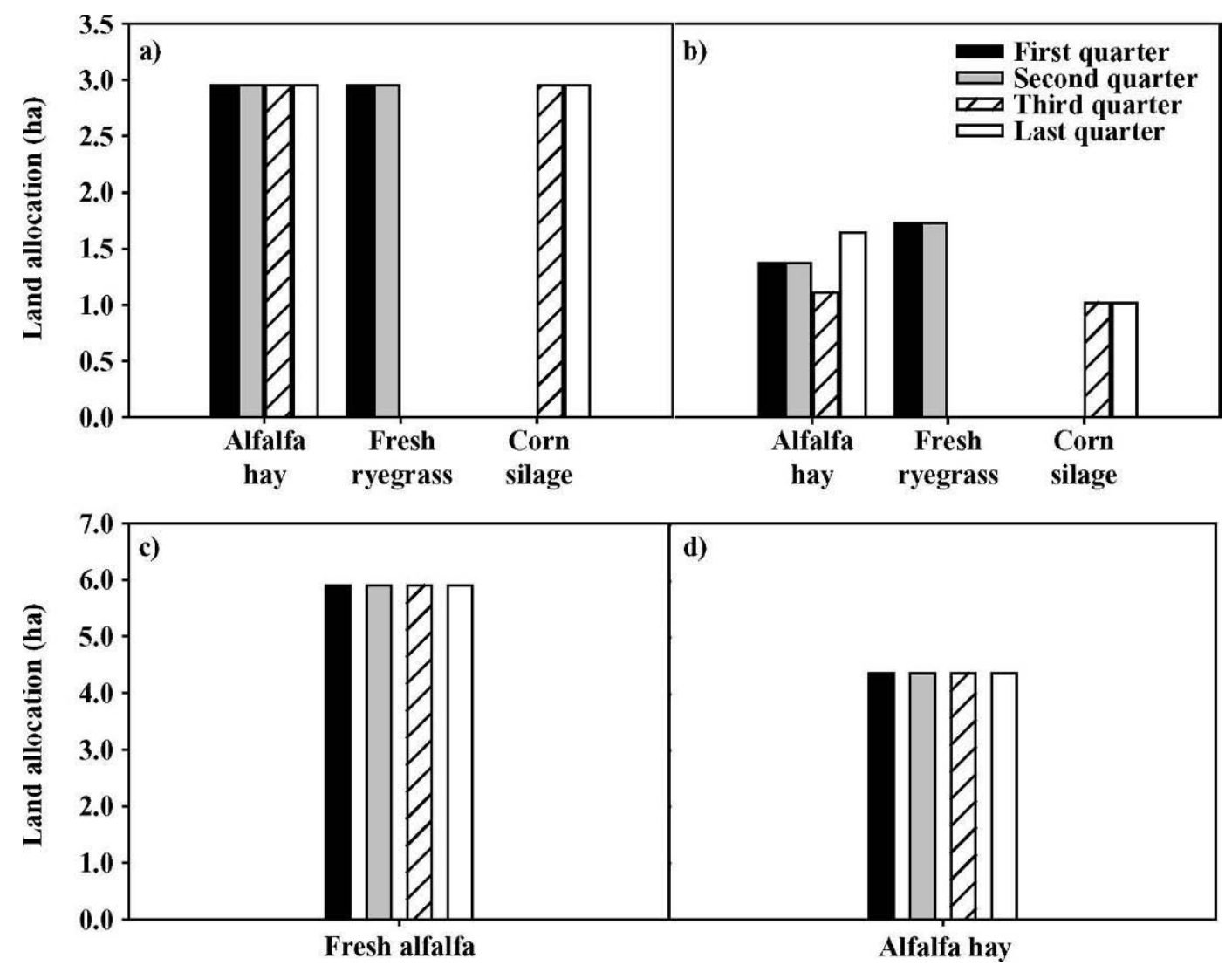

Figure 1. Land allocation from solutions of each single objective linear programming model: a) maximize ME for milk production, b) maximize margin over feed cost, c) maximize MP for milk production, and d) minimize purchased feeds.

tives specified in the pay-off matrix can be determined. In general there was underachievement with regard to the ideal points established in the pay-off matrix (Table 2 ). The only objective that was met by $\mathrm{CoP}$ was minimizing purchased feeds. The CoP model shows (similar to the GP model) that most of the cows should calve in the second and third quarters. However, the herd structure suggested by the CoP model gives higher milk production than the GP model (Table 6).

Table 7 also shows the best set of compromise solutions for $L_{1}$ and $L_{\infty}$. Like the GP model, the CoP model suggested a forage production strategy based on alfalfa, fresh ryegrass, and corn silage, and a similar pattern of land allocation. The land allocated differs from some of the LP solutions. The CoP model assigned the same land as the LP model that maximizes ME and more land than the one that maximizes margin. The feed costs, milk yield, DM supply, and DM required given by the compromise solutions are shown in Table 8. The milk cost generally showed more uniform values between quarters than those values obtained by the single objective LP models.

\section{DISCUSSION}

Based on the results shown in the previous section, 2 main issues require examination. First, whether MCDM is a better approach than ordinary LP for model-

Table 4. Optimal deviation variables from solving the goal-programming model

\begin{tabular}{lrrr}
\hline & Goal & Underachievement & $\begin{array}{c}\text { Overachievement } \\
\text { value }\left(p_{i}\right)\end{array}$ \\
\hline ME for milk production $(\mathrm{MJ})$ & $1,628,637$ & 11,511 & 0 \\
Margin over feed cost $(\mathrm{M} \$)$ & 169,285 & 0 & 87,732 \\
MP for milk production $(\mathrm{kg})$ & 14,178 & 490 & 0 \\
Cost of purchased feeds $(\mathrm{M} \$)$ & 0 & 0 & 39,483 \\
\hline
\end{tabular}


Table 5. Land allocation, feed cost, milk yield, DM supply, and DM required from the goal-programming model solution

\begin{tabular}{|c|c|c|c|c|c|}
\hline \multirow[b]{2}{*}{ Quarter } & & \multicolumn{4}{|c|}{ Land allocation (ha) } \\
\hline & & $\begin{array}{l}\text { Alfalfa } \\
\text { hay }\end{array}$ & $\begin{array}{l}\text { Fresh } \\
\text { alfalfa }\end{array}$ & $\begin{array}{l}\text { Fresh } \\
\text { ryegrass }\end{array}$ & $\begin{array}{l}\text { Corn } \\
\text { silage }\end{array}$ \\
\hline First & & - & 2.95 & 2.95 & - \\
\hline Second & & - & 2.95 & 2.95 & - \\
\hline Third & & - & 2.95 & - & 2.95 \\
\hline \multirow[t]{3}{*}{ Fourth } & & - & 2.95 & - & 2.95 \\
\hline & \multicolumn{5}{|c|}{ Feed and milk parameters } \\
\hline & $\begin{array}{l}\text { Feed cost } \\
(\mathrm{M} \$)\end{array}$ & $\begin{array}{l}\text { Milk yield } \\
\text { (L) }\end{array}$ & $\begin{array}{l}\text { Feed cost } \\
(\mathrm{M} \$ / \mathrm{L} \text { of milk })\end{array}$ & $\begin{array}{l}\text { DM supply } \\
(\mathrm{kg})\end{array}$ & $\begin{array}{l}\text { DM required } \\
(\mathrm{kg})\end{array}$ \\
\hline First & 22,420 & 14,127 & 1.59 & 54,940 & 13,561 \\
\hline Second & 22,420 & 4,760 & 4.71 & 54,940 & 6,786 \\
\hline Third & 22,420 & 13,679 & 1.64 & 49,809 & 10,215 \\
\hline Fourth & 22,420 & 15,358 & 1.37 & 49,232 & 13,334 \\
\hline
\end{tabular}

ing small-scale dairy enterprises, and second, whether the models provide a solid basis for decision-making aimed at improving the performance of such enterprises.

The pros and cons of GP and CoP have been pointed out in different works, with computational difficulties and lack of relevant information provided by the solutions noted as the main drawbacks experienced (Romero and Rehman, 1989; Piech and Rehman, 1993). When GP is used, there is a possibility of obtaining equivalent solutions to those from an LP version of the same problem. Barnett et al. (1982) applied GP to model a subsistence farm in Senegal. They also tried to de- velop a method of determining goal weights for the model. Their model did not improve on the performance of a profit-maximization LP model. The choice of a single objective function, however, is often equivocal, and in our case the GP model provided a coherent solution that differed from the single objective LP model solutions, which were quite diverse. Although all goals were assumed to have the same importance in this study, the GP model has the facility to incorporate weights that reflect preferences of the farmer or decision maker, giving an advantage over conventional LP.

The CoP approach represents a tool that offers flexibility in evaluating small-scale dairy enterprises

Table 6. Herd structure and milk production suggested by the goal and compromise programming models ${ }^{1}$

\begin{tabular}{|c|c|c|c|c|c|}
\hline \multirow[b]{2}{*}{ Stage } & \multicolumn{4}{|c|}{ Calendar quarter } & \multirow{2}{*}{$\begin{array}{l}\text { Milk yield } \\
\text { (L/cow per yr }\end{array}$} \\
\hline & First & Second & Third & Fourth & \\
\hline \multicolumn{6}{|l|}{ Goal programming } \\
\hline Calved + dry-off & 0.3 & 12.2 & 5.5 & 0.8 & \\
\hline First one-third & 0.5 & 0.3 & 6.7 & 5.5 & \\
\hline Second one-third & 5.5 & 0.5 & 0.3 & 6.7 & \\
\hline Last one-third & 6.7 & 0.0 & 0.1 & 0.0 & \\
\hline Milk yield (L) & 14,127 & 4,760 & 13,679 & 16,357 & 3,763 \\
\hline \multirow{2}{*}{\multicolumn{6}{|c|}{$\begin{array}{l}\text { Compromise programming } \\
L_{1}\end{array}$}} \\
\hline & & & & & \\
\hline Calved + dry-off & $\begin{array}{l}0.0 \\
23\end{array}$ & 6.1 & 4.6 & 2.3 & \\
\hline First one-third & 2.3 & 0.0 & 6.1 & 4.6 & \\
\hline Second one-third & 4.6 & 2.3 & 0.0 & 6.1 & \\
\hline Last one-third & 6.1 & 4.6 & 2.3 & 0.0 & \\
\hline Milk yield (L) & 14,934 & 10,700 & 13,679 & 15,332 & 4,204 \\
\hline \multicolumn{6}{|l|}{$L_{\infty}$} \\
\hline Calved + dry-off & 0.0 & 7.2 & 5.8 & 0.1 & \\
\hline First one-third & 0.1 & 0.0 & 7.2 & 5.8 & \\
\hline Second one-third & 5.8 & 0.1 & 0.0 & 7.2 & \\
\hline Last one-third & 7.2 & 5.8 & 0.1 & 0.0 & \\
\hline Milk yield (L) & 14,127 & 9,692 & 13,679 & 17,117 & 4,201 \\
\hline
\end{tabular}

${ }^{1} L_{1}$ (longest distance geometrically) and $L_{\infty}$ (largest deviation) denote the distance metrics considered by the compromise programming model. 
Table 7. Land allocation and most efficient compromise set for small-scale dairy farms according to the compromise programming model ${ }^{1}$

\begin{tabular}{|c|c|c|c|c|c|c|c|c|}
\hline \multirow[b]{3}{*}{ Quarter } & \multicolumn{8}{|c|}{ Land allocation (ha) } \\
\hline & \multicolumn{2}{|c|}{ Alfalfa hay } & \multicolumn{2}{|c|}{ Fresh alfalfa } & \multicolumn{2}{|c|}{ Fresh ryegrass } & \multicolumn{2}{|c|}{ Corn silage } \\
\hline & $L_{1}$ & $L_{\infty}$ & $L_{1}$ & $L_{\infty}$ & $L_{1}$ & $L_{\infty}$ & $L_{1}$ & $L_{\infty}$ \\
\hline First & & 2.64 & 2.95 & 0.31 & 2.95 & 2.95 & & \\
\hline Second & & 2.64 & 2.95 & 0.31 & 2.95 & 2.95 & & \\
\hline Third & & 2.64 & 2.95 & 0.31 & & & 2.95 & 2.95 \\
\hline \multirow[t]{2}{*}{ Fourth } & & 2.64 & 2.95 & 0.31 & & & 2.95 & 2.95 \\
\hline & \multicolumn{8}{|c|}{ Objective functions } \\
\hline Metrics & \multicolumn{2}{|c|}{$\begin{array}{l}\text { ME for milk } \\
\text { production }(\mathrm{MJ})\end{array}$} & \multicolumn{2}{|c|}{$\begin{array}{l}\text { Margin over feed } \\
\text { costs }(\mathrm{M} \$)\end{array}$} & \multicolumn{2}{|c|}{$\begin{array}{l}\text { MP for milk } \\
\text { production }(\mathrm{kg})\end{array}$} & \multicolumn{2}{|c|}{$\begin{array}{l}\text { Cost of purchased } \\
\text { feeds }(M \$)\end{array}$} \\
\hline$L_{1}$ & \multirow{2}{*}{\multicolumn{2}{|c|}{$\begin{array}{l}1,137,363 \\
1,185,428\end{array}$}} & \multicolumn{2}{|c|}{140,954} & \multicolumn{2}{|c|}{11,054} & \multicolumn{2}{|c|}{0.00} \\
\hline$L_{\infty}$ & & & \multicolumn{2}{|c|}{138,205} & \multicolumn{2}{|c|}{10,711} & \multicolumn{2}{|l|}{2,432} \\
\hline
\end{tabular}

${ }^{1} L_{1}=$ Longest distance geometrically; $L_{\infty}=$ largest deviation.

through the $L_{1}$ and $L_{\infty}$ metrics that enable the decision maker to select the best compromise. Piech and Rehman (1993) considered CoP to be the best option amongst MCDM techniques, in that $L_{1}$ and $L_{\infty}$ can be solved using 2 standard LP models. However, in the literature reviewed, applications of $\mathrm{CoP}$ were scarce, making it difficult to identify possible limitations in technique applicability. An interesting application of the technique was the study by Zekri and Romero (1992) to assess irrigation agriculture in a village in Spain to measure the opportunity cost of maintaining the current situation from the point of view of a public and private perspective. Their approach comprised 2 phases. First, a GP model was used to approximate the current situation, and second, a CoP model was used to assess the current situation in terms of criteria relevant to the perspectives mentioned above. In our case, the CoP model was not significantly better than the GP one, but applying both improved upon using a single objective LP model.

Regarding the second issue of this discussion, the system can be improved by effecting 2 main changes. The first is related to selection of the most appropriate forage production strategy by considering land avail- ability and cropping cycles. The second is by rescheduling the calving season to synchronize higher demand for nutrients with periods when forage availability is highest. According to the solutions provided by the GP and CoP models, an increase in nutrient (ME) availability by utilizing a larger land surface has a positive economic effect.

The forage production strategy selected by the models (basically comprising alfalfa, ryegrass, and corn silage) is similar to one (of several) identified in a previous work (Val-Arreola et al., 2004b). Dry matter supply by the forage production strategy suggested by our models was also in agreement with this identified strategy. The area proportion of forage to corn found in that work was in agreement with that suggested by the MCDM models (44:56; Table 7). These results were also consistent with the proportion given by Castelán-Ortega et al. (2003b).

In the work described herein, all the models selected similar ingredients to feed the animal, with most showing differences in the quantities recommended. Such quantities were dependent on the different objectives established and the type of model utilized to meet those

Table 8. Feed cost, milk yield, DM supply, and DM required according to the compromise programming model $^{1}$

\begin{tabular}{|c|c|c|c|c|c|c|c|c|c|c|}
\hline \multirow[b]{2}{*}{ Quarter } & \multicolumn{2}{|c|}{ Feed cost $(\mathrm{M} \$)$} & \multicolumn{2}{|c|}{ Milk yield (L) } & \multicolumn{2}{|c|}{ Milk cost $(\mathrm{M} \$ / \mathrm{L})$} & \multicolumn{2}{|c|}{ DM supply (kg) } & \multicolumn{2}{|c|}{ DM required $(\mathrm{kg})$} \\
\hline & $L_{1}$ & $L_{\infty}$ & $L_{1}$ & $L_{\infty}$ & $L_{1}$ & $L_{\infty}$ & $L_{1}$ & $L_{\infty}$ & $L_{1}$ & $L_{\infty}$ \\
\hline First & 9,434 & 12,899 & 14,934 & 14,127 & 0.63 & 0.91 & 32,863 & 37,946 & 13,817 & 13,768 \\
\hline Second & 9,434 & 10,467 & 10,670 & 9,992 & 0.88 & 1.08 & 32,863 & 33,812 & 9,667 & 8,963 \\
\hline Third & 15,818 & 13,679 & 13,679 & 14,703 & 1.16 & 0.93 & 43,808 & 43,043 & 10,796 & 10,008 \\
\hline Fourth & 15,512 & 14,878 & 14,332 & 17,117 & 1.01 & 0.87 & 42,952 & 43,716 & 12,239 & 13,780 \\
\hline
\end{tabular}

${ }^{1} L_{1}$ (longest distance geometrically) and $L_{\infty}$ (largest deviation) denote the distance metrics considered by the compromise programming model. 
objectives. For most of the cases, the feeding strategy was based on alfalfa, fresh ryegrass, and corn silage.

None of the models advocated supplementation with corn grain or commercial concentrate. Castelán-Ortega et al. (2003b) developed a simulation model for smallscale dairy farms in the highlands of Mexico that used corn straw, corn grain, and improved pasture as a feeding strategy. Previous work on small-scale dairy farms in Michoacan State have described feeding strategies based on fresh alfalfa, corn grain plus straw or commercial concentrate, according to availability and quality of forage, and in some cases a second forage such as oat hay (Val-Arreola, 1998; Méndez-y-Cazarín et al., 2000). Because our models considered factors like seasonality of forage availability, herd structure, herd requirements, and milk production, the solutions agree with studies that have pointed out that use of commercial concentrate in Mexico is determined by quality and availability of forage (Arriaga-Jordan et al., 2002; Castelán-Ortega et al., 2003b). To avoid such shortages, strategies that allow forage production over the whole year are needed. Arriaga-Jordan et al. (2002) suggest incorporating corn silage with the baseline forage. Schiere et al. (1999) suggest a way to adapt a farm is by matching quality and availability of resources with different types of animals to explore different adjustments between animals and feeds to achieve maximum system output. The way our models realized such adjustment was by allocating animals according to their lactation stage in each period of the year to match their nutritional requirements with available nutrients. Castelán-Ortega et al. (2003b) found using their model that the number of lactating cows was higher during the period with higher availability of feed of better quality (half of year). Our GP and CoP models allocated a higher number of lactating cows to the first and last quarters (Table 6).

Results obtained from the models provide information about how the forage strategy selected and the land utilized affect economic performance. Higher margins were obtained when most of the surface available was cultivated. Our models also provide information as to how forage shortage may be alleviated by modifying calving period to match nutrient availability with requirements at each lactation stage, with a minimum reduction in milk production. Excess of DM supply in relation to DM requirement in the case of the $\mathrm{CoP}$ and GP models agrees with previous work that suggested adopting a forage strategy based on alfalfa, ryegrass, and corn silage ensures that the nutrient requirements of the herd will be met (Val-Arreola et al., 2004b).

\section{ACKNOWLEDGMENTS}

Financial support for D. Val-Arreola was provided by the National Council of Science and Technology (CONACyT) of Mexico.

\section{REFERENCES}

Agricultural and Food Research Council (AFRC). 1993. Energy and protein requirements of ruminants. $\mathrm{CAB}$ International, Wallingford, UK.

Arriaga-Jordan, C. M., B. Albarran-Portillo, A. Espinosa-Ortega, A. Garcia-Martinez, and O. A. Castelan-Ortega. 2002. On-farm comparison of feeding strategies based on forages for small-scale dairy production systems in the highlands of central Mexico. Exp. Agric. 38:375-388.

Arriaga-Jordan, C. M., and R. A. Pearson. 2002. The contribution of livestock to small-holder livelihoods. Pages 21-22 in Responding to Increasing Global Demand for Animal Products. Proc. Br. Soc. Anim. Sci., Am. Soc. Anim. Sci., Mexican Soc. Anim. Prod., Univ. Yucatan, Merida, Mexico. Br. Soc. Anim. Sci., Edinburgh, UK.

Barnett, D., B. Blake, and B. A. McCarl. 1982. Goal programming via multidimensional scaling applied to Senegalese subsistence farms. Am. J. Agric. Econ. 64:720-727.

Candler, W. V. 1983. A demonstration model for the dairy industry of La Laguna. Pages 511-552 in The Book of CHAC: Programming Studies for Mexican Agriculture. R. D. Norton and L. Solis, ed. The John Hopkins University Press, Baltimore, MD.

Castelán-Ortega, O. A., R. H. Fawcett, C. Arriaga-Jordán, and M. Herrero. 2003a. A decision support system for smallholder campesino corn-cattle production systems of the Toluca Valley in Central Mexico. Part I-Integrating biological and socio-economic models into a holistic system. Agric. Syst. 75:1-21.

Castelán-Ortega, O. A., R. H. Fawcett, C. Arriaga-Jordán, and M. Herrero. 2003b. A decision support system for smallholder campesino corn-cattle production systems of the Toluca Valley in Central Mexico. Part II-Emulating the farming system. Agric. Syst. 75:23-46.

Cohon, J. 1978. Multiobjective Programming and Planning. Academic Press, New York, NY.

Dijkstra, J., J. France, M. S. Dhanoa, J. A. Maas, M. D. Hanigan, A. S. Rook, and D. E. Beever. 1997. A model to describe growth patterns of the mammary gland during pregnancy and lactation. J. Dairy Sci. 80:2340-2354.

Espinoza-Ortega, A., C. M. Arriaga-Jordan, and O. A. Castelan-Ortega. 1997. Economic analysis of the peasant production system at the Toluca Valley. Pages 94-102 in Proc. Small-Scale Dairy Syst., Toluca, Mexico. Autonomous University of Mexico State.

Gallardo-Nieto, J. L., L. Villamar-Angulo, H. Perez-Frias, and E. Olivera-Cazares. 2004. Current situation and perspectives of the Mexican dairy industry 2004. Ministry of Agriculture Bulletin (SAGARPA). http://www.sagarpa.gob.mx/Dgg/estudio/ sitlech04.pdf Accessed June 27, 2005.

Kebreab, E., J. France, D. E. Beever, and A. R. Castillo. 2001. Nitrogen pollution by dairy cows and its mitigation by dietary manipulation. Nutr. Cycl. Agroecosyst. 60:275-285.

Méndez-y-Cazarín, M. D., R. Tzintzun-Rascón, and D. Val-Arreola. 2000. Production evaluation, environmental effects and problems in small-scale dairy farms. Livest. Res. Rural Devel. 12(1). Online. Available: http://www.cipav.org.co//rrd//rrd12/1/manu121.htm Accessed Apr. 5, 2005. [Spanish with English abstract]

Piech, B., and T. Rehman. 1993. Application of multiple criteria decision-making methods to farm planning: A case study. Agric. Syst. 41:305-319.

Rehman, T., and C. Romero. 1993. The application of the MCDM paradigm to the management of the agricultural systems: some basic considerations. Agric. Syst. 41:239-255.

Romero, C., F. Amador, and A. Barco. 1987. Multiple objectives in agricultural planning: A compromise programming application. Am. J. Agric. Econ. 69:78-86.

Romero, C., and T. Rehman. 1989. Multiple Criteria Analysis for Agricultural Decisions. Elsevier, Amsterdam, The Netherlands.

Schiere, J. B., J. D. Wit, F. A. Steenstra, and H. V. Keulen. 1999. Design of farming systems for low input conditions: principles and implications based on scenarios studies with feed allocation in livestock production systems. Neth. J. Agric. Sci. 47:169-183. 
Val-Arreola, D. 1998. Maximisation of the margin of incomes over feed cost in small-scale dairy farms. M.Sc. Diss., Univ. Michoacan, Morelia, Mexico.

Val-Arreola, D., E. Kebreab, J. A. N. Mills, and J. France. 2005. Analysis of feeding strategies for small-scale dairy systems in central Mexico using linear programming. J. Anim. Feed Sci. 14:607-624.

Val-Arreola, D., E. Kebreab, J. A. N. Mills, and J. France. 2004a. Optimising the calving pattern of herds in small-scale dairy systems in central Mexico. J. Anim. Feed Sci. 13:557-573.

Val-Arreola, D., E. Kebreab, J. A. N. Mills, S. Wiggins, and J. France. 2004b. Forage production and nutrient availability in small-scale dairy systems in central Mexico using linear programming and partial budgeting. Nutr. Cycl. Agroecosyst. 69:191-201.

Val-Arreola, D., E. Kebreab, J. Dijkstra, and J. France. 2004c. Study of the lactation curve in dairy cattle on farms in central Mexico. J. Dairy Sci. 87:3789-3799.

Wiggins, S. 2002. Small-scale dairying as the key piece in the rural livelihoods. Pages 197-210 in Proc. New Trends in the Socioeconomic Analysis of the Dairy Industry in the Globalisation Context, Toluca, Mexico. Autonomous University of Mexico State.

Zekri, S., and C. Romero. 1992. A methodology to assess the current situation in irrigated agriculture: An application to the village of Tauste (Spain). Oxf. Agrar. Stud. 20:75-88.

\section{APPENDIX}

Appendix 1. Summary of constraints

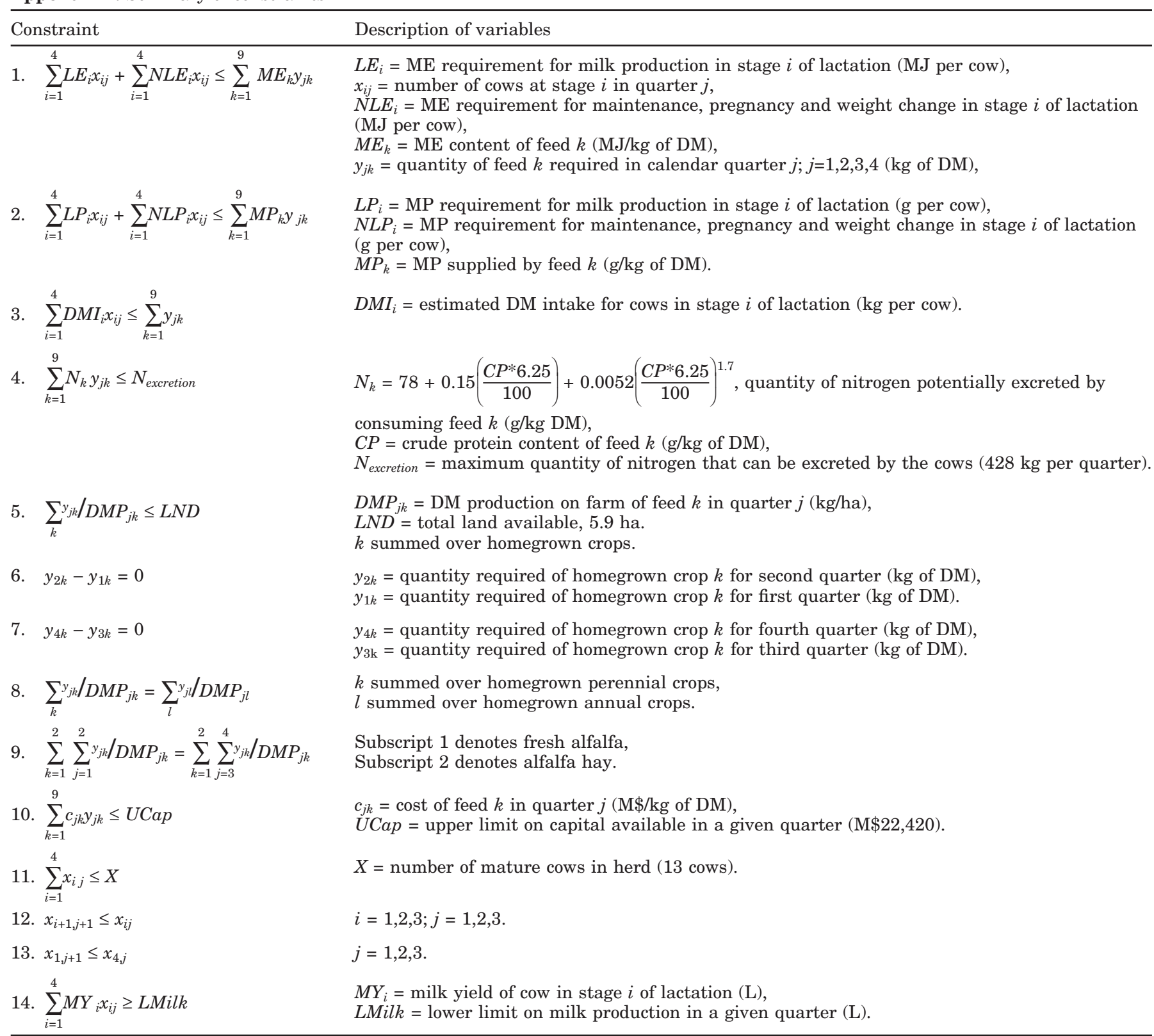


VAL-ARREOLA ET AL.

Appendix 2. Summary of objective functions

\begin{tabular}{lll}
\hline Objective & Function & Description of variables \\
\hline 1. Maximize ME for milk production. & $\sum_{j=1}^{4}\left(\sum_{k=1}^{9} M E_{k} y_{j k}-\sum_{i=1}^{4} N L E_{i} x_{i j}\right)$ & \\
2. Maximize margin over feed cost & $\sum_{j=1}^{4}\left(\sum_{i=1}^{4} M Y_{i} p_{j} x_{i j}-\sum_{k=1}^{9} c_{i k} y_{j k}\right)$ & $p_{j}=$ milk price in quarter $j(\mathrm{M} \$ / \mathrm{kg})$ \\
3. Maximize MP for milk production & $\sum_{j=1}^{4}\left(\sum_{k=1}^{9} M P_{k} y_{j k}-\sum_{i=1}^{4} N L E_{i} x_{i j}\right)$ & \\
4. Minimize purchased feeds & $\sum_{j=1}^{4} \sum_{k} c_{j k} y_{j k}$ & $k$ summed over purchased feeds \\
\hline
\end{tabular}

